\title{
Comunicação Política e educação: desenvolvimento de capacidades deliberativas entre jovens da rede pública de ensino no Brasil'
}

ARTIGO ORIGINAL

POLITICAL COMMUNICATION AND EDUCATION: DEVELOPING DELIBERATIVE CAPACITIES AMONG STUDENTS FROM E PUBLIC SCHOOLS IN BRAZIL

\section{Érica Anita Baptista}

Jornalista e doutora em Ciência Política pela Universidade Federal de Minas Gerais (UFMG). Pesquisadora de pós-doutorado no Grupo de Pesquisa em Mídia e Esfera Pública (EMEUFMG). Pesquisadora no grupo Opinião Pública (UFMG) e no Centro de Investigação Media e Jornalismo (Universidade Nova de Lisboa).

E-mail: anitaerica@gmail.com

\section{Fernanda Nalon Sanglard}

Jornalista e doutora em Comunicação Social pela Universidade Estadual do Rio de Janeiro (UERJ). Pesquisadora de pós-doutorado no Grupo de Pesquisa em Mídia e Esfera Pública (EME-UFMG).

E-mail: nandanalon@yahoo.com.br

\section{Danila Gentil Cal}

Professora Adjunta da Faculdade de Comunicação e do Programa de Pós-Graduação em Comunicação Social da Universidade Federal do Pará (UFPA). Pesquisadora do Grupo de Pesquisa em Mídia e Esfera Pública (EME-UFMG). É líder do Grupo de Pesquisa Comunicação e Política na Amazônia (Compoa - UFPA/CNPq).

E-mail: danilagentilcal23@gmail.com

\section{Ana Carolina Vimieiro}

Professora Adjunta do Departamento de Comunicação Social da Universidade Federal de Minas Gerais (UFMG). Pesquisadora do Grupo de Pesquisa em Mídia e Esfera Pública (EME-UFMG).

E-mail: anacarolsco@gmail.com

1. Pesquisa financiada por: CAPES-SECADI 


\section{Rousiley Celi Moreira Maia}

Professora Titular do Departamento de Comunicação Social da Universidade Federal de Minas Gerais (UFMG). Líder do Grupo de Pesquisa em Mídia e Esfera Pública (EMEUFMG).

E-mail: rousiley@gmail.com

\section{Vanessa Oliveira Veiga}

Professora Adjunta do Departamento de Comunicação Social da Universidade Federal de Minas Gerais (UFMG). Pesquisadora do Grupo de Pesquisa em Mídia e Esfera Pública (EME-UFMG).

E-mail: veiga.jornalismo@gmail.com

\section{Resumo}

Este artigo explora experiências internacionais que envolvem a prática da deliberação em escolas e apresenta os passos da primeira experiência voltada para a aprendizagem e o treinamento de capacidades deliberativas no Brasil. Fundamentadas nas teorias da democracia deliberativa, tais iniciativas são primordialmente interdisciplinares, ao estabelecer interfaces com estudos nos campos da Comunicação, Ciência Política e Educação, entre outras áreas. Este artigo busca contribuir com pesquisas comunicacionais que visam à intervenção social no que tange à resolução de conflitos, modelos de discussão colaborativa e convivência democrática no âmbito escolar.

Palavras-chave: Deliberação. Escolas. Comunicação política. Democracia. Conflito.

\section{Abstract}

This article surveys a range of international initiatives that involves the practice of deliberation in schools. It provides an outline of the first Brazilian experience aiming at producing learning and training of deliberative capacities in students. Based on theories of deliberative democracy, these types of experience are interdisciplinary, by establishing interfaces with studies in the field of Communication, Political Science and Education, among other areas. This paper contributes to advancing communication research that focus on social interventions regarding conflict resolution, collaborative discussion models and democratic coexistence in the context of schools.

Keywords: Deliberation. Schools. Political communication. Democracy. Conflict. 


\section{Introdução}

A teoria da democracia deliberativa tem atraído continuamente a atenção de pesquisadores de campos de conhecimento cada vez mais diversos (DRYZEK, 2007, 2010; MANSBRIDGE ET AL., 2012; NEBLO, 2015). A comunicação interpessoal encontra-se no centro das práticas deliberativas; sendo que muitas pesquisas no campo da democracia deliberativa fundamentam experiências práticas para inovar a participação dos cidadãos em processos de decisão coletiva, para aperfeiçoar o conhecimento político e desenvolver habilidades cívicas; para promover aprendizagem coletiva sobre questões de interesse comum, e, ainda, para a resolução de conflitos. O presente artigo apresenta uma revisão de literatura concernente a experiências envolvendo o conceito de deliberação aplicado ao ambiente escolar. O mapeamento dessas experiências é importante para que se melhor compreenda a construção de um projeto pioneiro no campo dos estudos sobre democracia, comunicação política e o ensino de capacidades deliberativas no Brasil.

As discussões propostas neste artigo estão organizadas em quatro seções. Na primeira parte, examinamos a relação entre Comunicação, Deliberação e Inovação. Em seguida, discutimos os principais estudos que envolvem práticas de intervenção social baseadas na deliberação em ambiente escolar em outros países. Focalizamos, em particular, os pontos considerados positivos e negativos dessas experiências, e, ainda, os desafios metodológicos para implementar e conduzir essas iniciativas. Por fim, apresentaremos os propósitos e os passos iniciais da pesquisa Deliberação em escolas públicas: criando capacidades deliberativas, a primeira experiência dessa natureza no Brasil. Uma das inovações da iniciativa nacional é o fato dela, diferentemente dos casos internacionais estudados, visar primordialmente verificar se é possível ensinar habilidades deliberativas e identificar quais seriam os métodos mais eficazes.

O objetivo do projeto em questão é, por meio de recursos pedagógicos específicos com diversas interfaces com os media, oferecer oportunidades para que estudantes aprendam na prática, e desde cedo, como funciona a deliberação. Dessa forma, espera-se promover capacidades deliberativas entre estudantes, fomentando o respeito, a inclusão e a eficiência no engajamento discursivo sobre conflitos e sobre questões controversas em geral. O projeto em questão possui relevância teórica, metodológica e prática, porque a deliberação vem sendo reconhecida como um meio altamente eficaz para criar compreensão esclarecida de problemas, entendimento mútuo, tolerância e participação produtiva na resolução de conflitos, do nível local até a política internacional. Garante, sobretudo, a legitimidade na produção de decisões políticas. 
Em termos teóricos, a pesquisa faz avançar o conhecimento sobre os elementos que promovem ou obstruem a deliberação em grupos de discussão face-a-face (STEINER et al., 2017). No âmbito metodológico, a iniciativa em tela prevê a utilização original de recursos e práticas de mídia em experimentos para o ensino e a aprendizagem de capacidades deliberativas com jovens do ensino médio em escolas públicas brasileiras. Por fim, em termos práticos, esta proposta visa produzir conhecimento inovador para que a iniciativa em questão possa ser replicada, ao oferecer subsídios para a implantação do ensino das capacidades deliberativas em escala ampliada.

\section{Comunicação, Deliberação e Inovação}

O conceito de deliberação - oriundo majoritariamente da obra do filósofo Jürgen Habermas - refere-se basicamente ao processo de discussão pública, fundado na troca de argumentos e em considerações refletidas sobre questões controversas, com vistas à produção de decisões mutuamente aceitáveis. Segundo Habermas, "a deliberação é uma forma exigente de comunicação, embora emerja de rotinas diárias imperceptíveis de demanda e fornecimento de argumentos" (HABERMAS, 2006, p. 413, tradução nossa). De modo geral, podemos entender deliberação como um processo no qual dois ou mais agentes ponderam sobre as razões envolvidas em certa questão. É uma atividade necessariamente interativa que pressupõe uma noção de política baseada na troca de argumentos entre os sujeitos de forma não-coercitiva. A deliberação pode produzir uma melhor compreensão do problema sob diversos ângulos, ampliando a possibilidade de encontrar soluções mutuamente aceitáveis, através da modificação e revisão das posições. As interações entre os interlocutores, considerados com igual status moral e político, devem basear-se na escuta atenta e no respeito recíproco às opiniões divergentes.

A teoria da democracia deliberativa inclui diferentes "fases". Após um intenso debate, desde 1990, sobre as controvérsias filosóficas e teóricas em torno dos princípios e das normas da deliberação, seguiu-se, desde 2000, a fase de implementação empírica de experiências deliberativas em diversas regiões do mundo. No recente e vibrante debate sobre o conceito de "sistema deliberativo", considerada a terceira fase neste campo de estudos, pesquisadores têm defendido a adoção de uma agenda de pesquisa capaz de aprofundar o entendimento da deliberação como um processo social amplo. Um dos desafios atuais é construir práticas de deliberação em larga escala (DRYZEK, HENDRIKS, 2012; HENDRIKS, 2006; GOODIN, 2005; MANSBRIDGE et al., 2012; NEBLO, 2005; 
PARKINSON, 2006; THOMPSON, 2008). Pesquisas prévias neste campo vêm investigando processos deliberativos em diferentes instituições e fóruns, em ambientes parlamentares, em minipúblicos (ELSTUB, MCLAVERTY, 2014; GRÖNLUND, et al., 2014; STASAVAGE, 2007; STEINER et al., 2004; WARREN, PEARSE, 2008), e, ainda, em ambientes digitais (COLEMAN, MOSS, 2012; KIES, 2010; KIES, MANZ, 2013; MAIA; RESENDE, 2016; STRANDBERG, GRÖNLUND, 2014; STROMER-GALLEY, WICHOWSKI, 2011). As abordagens mais recentes têm apresentado como desafio futuro desenvolver conhecimento e práticas a fim de "ampliar a deliberação para a sociedade como um todo" (BÄCHTIGER, WEGMANN, 2014; MANSBRIDGE et al., 2012; NIEMEYER, 2014; STEVENSON, DRYZEK, 2014). Por meio da pesquisa aplicada, entendemos que é possível lidar com esse desafio.

$\mathrm{Na}$ área da educação, a importância da deliberação para a resolução de conflitos também tem sido reconhecida. Pesquisadores dessa área têm recentemente confirmado que as habilidades, os conhecimentos, as atitudes e os valores necessários para deliberar podem ser ensinados e aprendidos em sala de aula (SAMUELSON, BOYUM, 2015). O impacto da noção de democracia deliberativa é mais notório nos Estados Unidos e na Europa, onde, na última década, têm proliferado programas educacionais que buscam cultivar em alunos de diferentes níveis as competências necessárias para o diálogo e para a resolução colaborativa de problemas (GERSHTENSON et al., 2010; FELDMAN et al., 2007; O'CONNELL, MCKENZIE, 1995; GASTIL, DILLARD, 1999). No Brasil, não temos conhecimento da implementação de qualquer programa de educação que procure fomentar uma cultura deliberativa entre os jovens. Por isso, o projeto que propomos "Deliberação em escolas públicas" é considerado a primeira proposta para desenvolver um programa de educação cidadã a partir do conceito de deliberação no país.

O ambiente escolar é um espaço privilegiado para o aprimoramento das habilidades e competências de jovens. Após a família, a escola é o segundo principal espaço de socialização de crianças e adolescentes. Em razão da complexidade das relações que aí acorrem e, ainda, da precariedade do ensino público no país, a escola tem se tornado um lócus fértil para identificação de conflitos que envolvem preconceitos e intolerância, como a homofobia, o sexismo, o racismo, entre outras formas de injustiças (DAYRELL et al., 2013; GARCIA et al., 2017; ABROMOVAY et al.; 2002). De tal sorte, aprimorar as capacidades deliberativas entre os agentes da escola é uma forma de desenvolver a capacidade dos jovens de expressar seus posicionamentos, de justificá-los e refletir sobre eles, a partir da interação com os outros. Em termos concretos, essas capacidades deli- 
berativas permitem criar disposição para dialogar, deliberar e ouvir; motivar a tolerância e o respeito para com o ponto de vista do outro; incentivar a colocar-se no lugar do outro; desenvolver atenção ao bem comum e, com, isso o respeito ao direito dos outros (MAIA, 2014; STEINER, 2012; STEINER et al., 2017). De modo imediato, aprender as capacidades necessárias a deliberação contribui para resolver conflitos através do diálogo construtivo, com potencial para transformar de modo positivo as relações no contexto escolar e na comunidade local. Em longo prazo, essas capacidades são essenciais para o desenvolvimento pleno de cidadãos.

\section{As experiências internacionais de educação em deliberação}

A partir da conviç̧ão de que os cidadãos podem aprimorar suas habilidades cívicas e políticas, quando têm a oportunidade de aprender sobre questões de interesse comum e de se engajarem em grupos de discussões face a face, os Estados Unidos construíram uma longa trajetória de programas de educação cívica. Diversas dessas experiências envolvem a participação de cidadãos em fóruns organizados com o objetivo de incentivar a discussão entre pessoas pertencentes a diferentes estratos sociodemográficos e com distintas origens culturais, étnicas e religiosas (BORMANN, 1996; FISHKIN, 1995; GASTIL; DILLARD, 1999). A experiência dos Fóruns de Questões Nacionais (National Issues Forums - NIF), iniciada em 1982 e que atualmente funciona como um instituto não governamental ${ }^{2}$, chamou a atenção dos pesquisadores do campo da Comunicação pelo fato de se inspirar nos modelos procedimentais de deliberação. Em 1989, essa rede da sociedade civil se transformou em Instituto NIF, com o objetivo de estimular a deliberação pública nos Estados Unidos, tendo em vista os baixos níveis de educação cívica neste país. Esta iniciativa visa desenvolver a discussão sobre questões de política em âmbito local e nacional, por meio de fóruns organizados com um número pequeno de participantes, a fim de criar lideranças que possam expandir os resultados dessas discussões e, também, exercer influência junto a agentes produtores de decisão política naquele país.

Gastil e Dillard (1999), ao examinar a experiência do NIF, enfatizam a importância do papel do moderador nos grupos de discussão para desenvolver a capacidade de agência -dos participantes, e para o compartilhamento da responsabilidade pela tomada de decisão entre os membros do grupo. Segundo esses autores, o NIF é um exemplo de desenvolvimento de liderança democrática em pequenos grupos. Entre os resultados positivos, eles

2. Disponível em: $<$ https://www.nifi.org/es>. Acesso em: 21 julho 2018. 
destacam, ainda, que a iniciativa em tela promove um aumento do interesse pela política, a possibilidade de mudança de opinião e, também, maior grau de engajamento cívico.

Todavia, percebe-se que o método utilizado pelo NIF se concentra fortemente no conteúdo dos tópicos selecionados para discussão. Uma vez que a preocupação central é a de elevar o nível de conhecimento dos participantes sobre um dado assunto, esta iniciativa aproxima-se de programas de natureza conteudística. E, apesar de ser um método de educação cívica baseado em discussões, não é necessariamente realizado no ambiente escolar. Neste sentido, o exame de outras experiências, com maior especificidade na teoria e prática da deliberação, é necessário para melhor qualificar o projeto "Deliberação em escolas públicas".

Entre 1994 e 1996, é possível notar outra iniciativa sobre deliberação no ambiente escolar, conduzida nos Estados Unidos. Holt et al. (1998) destacam que esta experiência buscou compreender o uso da tecnologia em grupos de estudo online, como fóruns universitários. Durante seis semanas, essas pesquisadoras analisaram as conversações e postagens de estudantes de duas universidades americanas, Ithaca College e University of Georgia, a partir da análise dos fóruns de discussão. Conseguiram identificar estágios de deliberação (pré-deliberação, quase deliberação e deliberação) nas conversações que ocorreram ao longo dos fóruns. Entretanto, o estudo se deparou com uma série de limitações, incluindo períodos curtos de tempo para a experiência (encontros online durante seis semanas) e dificuldades tecnológicas (para muitos participantes, tratava-se de uma novidade), reportadas também pelos participantes, e, ainda, o fato de envolver participação obrigatória, ao invés de espontânea, dos estudantes. Ainda que outras pesquisas demonstrem que a participação obrigatória ou estratégias de opt-out (consentimento passivo) - quando estudantes são incluídos em uma pesquisa a menos que se recusem explicitamente a participar - resultem em amostras mais representativas do que a participação espontânea (TESTA; COLEMAN, 2006; UNGER et al.., 2004; DENT et al., 1993), questões éticas sempre dificultam a escolha por tais estratégias já que implicam em certo grau de coerção e indução não voluntária da participação, o que se torna bastante sensível quando a pesquisa envolve crianças e adolescentes e a discussão de tópicos controversos. Além disso, no caso do cenário brasileiro, Pereira e colegas (2012) esclarecem que juridicamente só é possível a abordagem do opt-in (consentimento ativo) em pesquisas escolares com adolescentes.

Um projeto realizado na Suécia, ao longo do ano de 2002, também chama a atenção neste campo de experiências. Conforme Thornberg (2010), a iniciativa visava prepa- 
rar jovens para serem cidadãos comprometidos, ativos e competentes em uma democracia. Em particular, tinha como propósito estimular os estudantes a se tornarem críticos a movimentos totalitários, por meio da prática de educação democrática e participação estudantil, na escola primária. Através de estudo etnográfico, Thornberg examinou os valores formais e informais da educação no cotidiano escolar, a partir da interação dentro de sala de aula. Diferentemente das experiências apresentadas anteriormente neste artigo, o idealizador da iniciativa sueca não propôs uma atividade deliberativa, mas, ao invés disso, observou se tal prática se concretizava espontaneamente. Dentre os métodos utilizados por Thornberg (2010) para a coleta de dados estão: a observação e gravação de áudio de "reuniões plenárias" - que já eram uma atividade da escola - durante um ano, anotações de campo, observações etnográficas cotidianas por três semanas, entrevistas em grupo com estudantes e entrevistas individuais com professores. No total, a pesquisa envolveu cerca de cem alunos com idade entre 6 e 8 anos e seis professores.

Conforme Thornberg (2010), as "reuniões plenárias" realizadas pela escola envolviam o método de Iniciação-Resposta-Sequência (Initiation-Response-Follow-up - IRF) e a moderação era feita por um professor, enquanto outra pessoa controlava a pauta e tomava notas. Este pesquisador percebeu nesse tipo de interação algo previamente apontados por Giordan (2003, p. 818): que as trocas baseadas no modelo IRF disfarçam a reprodução cultural por meio da simulação da participação dos alunos, enquanto o professor guia a interação e desempenha o papel de transmissor de informações. Em outras palavras, nas interações do IRF, a assimetria de poder entre professores e alunos é reproduzida de acordo com os papéis tradicionais do ambiente escolar (THORNBERG, 2010). Desse modo, apesar da proposta da escola em estimular discussões democráticas, a postura de autoridade dos professores acabava por comprometer a discussão e afastá-la dos ideais da deliberação. Assim sendo, o projeto brasileiro compreende que a comunicação nos grupos de discussão deve ser democrática e não disciplinadora. Por isso, testar se os momentos de deliberação funcionam melhor com ou sem a presença dos professores é uma questão relevante em nossa pesquisa.

Por fim, uma das iniciativas de maior porte na área circunscrita refere-se ao projeto Deliberating in a Democracy (DID) e a sua extensão, o projeto Expanding Deliberating in a Democracy. Estes, foram desenvolvidos entre os anos de 2004 e 2010, sendo o Expanding iniciado a partir de 2008, sob supervisão da Fundação de Direitos Constitucionais de Chicago (CRFC), da Fundação de Direitos Constitucionais de Los Angeles (CRF) e da Street Law Inc., contando com apoio financeiro do Departamento de Educação dos EUA. O objetivo 
foi o de ensinar professores e estudantes de dez países (Azerbaijão, EUA, Estônia, Lituânia, Macedônia, República Tcheca, Romênia, Rússia, Sérvia e Ucrânia) como deliberar na sala de aula sobre questões públicas controversas (AVERY et al., 2013).

Para a condução deste projeto, os professores passaram por uma capacitação em mais de três encontros anuais. Nessas sessões, os professores aprenderam um modelo específico de discussão denominado "Controvérsia Acadêmica Estruturada" (Structured Academic Controversy - $S A C$ ), o qual foi usado em turmas secundaristas. Como explicam Avery et al. (2013), o modelo SAC, desenvolvido por Johnson e Johnson (1979; 2003), se trata de uma sequência de passos em que os estudantes examinam dois lados de uma questão, sendo um posicionamento "a favor" e outro "contra". O professor procede com a divisão da sala em grupos heterogêneos de quatro e uma posição "a favor" é atribuída a dois estudantes enquanto dois outros preparam uma posição "contra". O DID alcançou mais de 20 mil estudantes secundaristas, com idade entre 12 e 19 anos, e 400 professores. Como resultado, os empreendedores deste projeto constataram que os alunos envolvidos nesta iniciativa alcançaram melhores resultados quanto às habilidades para expressão da própria opinião, a consideração e a crítica da opinião dos outros em comparação àqueles não participantes do DID. Ao longo dos anos, os estudantes compreenderam os ganhos de sua participação nas deliberações do projeto (AVERY et al., 2013).

Um dos projetos mais próximos da iniciativa que está sendo desenvolvida no "Deliberação em escolas públicas" é o Student Voices, realizado nos Estados Unidos. O estudo de Feldman et al. (2007) explora os efeitos de longo prazo de uma intervenção de educação cívica planejada especificamente para fomentar o engajamento político. O Student Voices foi realizado entre 2002 e 2004 em 26 escolas de ensino médio, envolvendo 1.782 estudantes. Este volume de estudantes não inclui a etapa de diagnóstico, que foi conduzida com cerca de 500 alunos. Esta proposta tem por objetivo, entre outros, identificar as práticas mais bem-sucedidas para a educação cívica.

\section{A proposta brasileira}

O projeto "Deliberação nas Escolas Públicas: criando capacidades deliberativas", envolve um diálogo crítico entre a literatura sobre deliberação, comunicação política e educação. Há já um acúmulo de conhecimento decorrente de programas educacionais sobre deliberação existentes em outros países, os quais nos permite analisar as concepções, as lógicas, os métodos e os exemplos práticos dessas experiências. No entanto, nossa 
proposta pretende ir além dessas iniciativas, ao incluir algumas inovações importantes. Primeiro, a pesquisa que desenvolvemos recentemente, em parceria com o Prof. Jürg Steiner, da Universidade de Berna, na Suíça, e da Universidade da Carolina do Norte, em Chapel Hill, nos Estados Unidos, produziu uma descrição sistemática de elementos que ajudam a fomentar ou a obstruir as capacidades deliberativas. Nessa pesquisa anterior, investigamos dinâmicas de discussão entre grupos que nutrem profundas divisões (STEINER; JARAMILLO; MAIA; MAMELI, 2017). Para tanto, foram formados grupos de discussão com ex-guerrilheiros e ex-paramilitares na Colômbia; com Sérvios e Bósnios em Srebrenica, na Bósnia-Herzegovina; e com residentes de comunidades pobres e policiais militares no Brasil. Esses grupos discutiram o modo através do qual as relações entre eles podem se tornar mais pacíficas, justas e democráticas. Ao analisar essas discussões, avaliamos o papel de justificações, histórias pessoais, sarcasmo, humor, o silêncio e de líderes que facilitam ou dificultam o debate. Em contraste com experiências educacionais prévias, portanto, temos em mãos uma decomposição analítica de elementos que promovem ou obstruem a deliberação ${ }^{3}$. Dessa forma, o estudo oferece um conjunto extensivo de dados que podem ser convertidos em material pedagógico destinado a ajudar crianças e adolescentes a desenvolver, desde cedo, suas capacidades deliberativas.

Em segundo lugar, o projeto em causa, ao invés buscar primordialmente ampliar o conhecimento sobre um dado assunto, visa criar estratégias e fornecer recursos para que os estudantes construam uma consciência reflexiva sobre os comportamentos e as atitudes que tornam a deliberação bem-sucedida. Utilizando as gravações e transcrições das discussões em grupo realizadas no Brasil, na Colômbia e na Bósnia-Herzegovina, temos por meta produzir instrumentos pedagógicos apropriados, baseados em conflitos autênticos. No contexto brasileiro, alguns projetos educacionais voltados para a educação cidadã, têm envolvido estudantes em discussões sobre direitos e cidadania, ainda que a noção de deliberação em si não seja aplicada diretamente no planejamento das ações. Podemos mencionar como exemplos o Parlamento Jovem Brasileiro e o projeto Adolescentes Protagonistas. São iniciativas de grande relevância, mas não são dedicadas à capacitação para a deliberação, uma vez que focalizam, assim como as experiências internacionais, sobretudo o aprendizado de um determinado conteúdo (como as atividades de parlamentares, questões de direito, de cidadania ou de orçamento público). Em nosso projeto, nosso intuito é o de estudar os princípios da deliberação com exemplos concretos de atitudes e comportamentos fa-

3. Os resultados foram reunidos no livro Deliberation Across Deeply Divided Societies, publicado pela editora Cambridge University Press, em março de 2017. 
voráveis e desfavoráveis à esta prática Embora tratemos de temas controversos atuais da conjuntura política brasileira, e de conflitos sociais que disputam atenção e opinião nos media, desenvolvemos um material didático, adaptado ao contexto escolar, para colocar em prática e promover a reflexão sobre as capacidades deliberativas no fluxo das interações comunicativas.

Por fim, nossa proposta, ao atuar com jovens da rede pública de ensino, busca lidar com o atual desafio na agenda de pesquisa sobre sistema deliberativo, qual seja "ampliar a deliberação para a sociedade como um todo" (BÄCHTIGER; WEGMANN, 2014; MANSBRIDGE et al., 2012; STEVENSON; DRYZEK, 2014). Esperamos, portanto, que, aliando a teoria à prática, as capacidades deliberativas sejam impulsionadas. Pesquisadores confirmam que as habilidades, os conhecimentos, as atitudes e os valores necessários para deliberar podem ser ensinados e aprendidos em sala de aula (SAMUELSON; BOYUM, 2015).

Numa visão de conjunto, este projeto possui o potencial para ser replicado em larga escala. A deliberação, como já mencionado, vem sendo reconhecida como um meio altamente eficaz para criar compreensão esclarecida de problemas, entendimento mútuo, tolerância e participação produtiva na resolução de conflitos, do nível local até a política internacional. Na medida em que esta prática envolve diretamente os cidadãos na definição dos problemas e na busca colaborativa por soluções - ou seja, soluções que sejam mutualmente aceitáveis ou igualmente boas para os participantes - garante, sobretudo, a legitimidade na produção de decisões políticas. Nesse sentido, o presente projeto pode ter efeitos positivos de longo prazo. Ao apostar nessa longevidade, a equipe dessa iniciativa vem elaborando materiais didáticos - tais como vídeos, dinâmicas de performances deliberativas, jogos, entre outros - de modo que o desenvolvimento e aprimoramento das capacidades deliberativas sejam replicados em outras escolas e a diversos públicos. Ademais, um aparato para aferir a eficácia dessas iniciativas em nosso experimento vem sendo desenvolvido, envolvendo grupos de treinamento e grupo de controle, questionários, técnicas de "follow up" e análises estatísticas.

Não obstante à expectativa de sucesso e de reprodução dessa iniciativa, esbarramos em questões metodológicas relativas à expertise das áreas envolvidas. Temos, portanto, aliado a literatura sobre deliberação, Comunicação e Educação, com vistas a nos aproximar do contexto escolar brasileiro, a fim de lidar com os desafios inerentes à educação pública no país. 


\section{Questões metodológicas aplicadas ao experimento}

O projeto Deliberação em escolas públicas pretende atuar com jovens do período final do ciclo básico (nono ano) ao ensino médio em escolas da periferia da rede pública de duas cidades (e regiões metropolitanas): Belo Horizonte e Belém. Estas cidades, localizadas em diferentes regiões - Sudeste e Norte, respectivamente -, possuem realidades próprias e poderão oferecer um bom diagnóstico das especificidades dos problemas de violência e violação de direitos humanos enfrentados nesses contextos.

Os estudos da comunicação, por meio das práticas de deliberação, surgem nesse sentido como uma possibilidade para se lidar com conflitos e para explorar temas que dividem opiniões em nosso país. A presente iniciativa pretende construir capacidades e comportamentos que sustentam uma convivência democrática e uma cultura de paz, sem, contudo, almejar criar unanimidades ou o apagamento das diferenças. Pelo contrário, essa iniciativa foi idealizada para estimular o respeito às diversidades.

Para melhor entender como o projeto brasileiro foi delineado, seguem descritas abaixo as quatro etapas de execução do projeto:

1) Planejamento: Elaboração de questionários, de material didático próprio, envolvendo textos, jogos, material multimídia, etc. que contenham exemplos detalhados e autênticos sobre as capacidades deliberativas, a partir de pesquisas já realizadas. Esta fase envolve também o projeto piloto, que visa testar em escala reduzida a proposta e permitir ajustes nas ferramentas que serão utilizadas.

2) Aprendizagem das capacidades deliberativas: Interação dos pesquisadores com gestores escolares, professores e alunos no ambiente escolar. Integração dos professores na preparação das oficinas. Aplicação de questionários, realização de oficinas temáticas para treinamento das capacidades deliberativas entre os alunos e de grupos de discussão baseados no método do grupo focal. Os questionários serão compostos por questões sociodemográficas e relativas às atitudes e capacidades deliberativas - no início e no fim da pesquisa. O objetivo dos questionários é conhecer melhor o contexto em que os estudantes vivem e auxiliar a medir as atitudes em relação à deliberação antes e depois de passarem pelo treinamento.

3) Avaliação do impacto: Fase de análise dos dados coletados por meio de questionários, oficinas para treinamento das capacidades deliberativas e grupos de discussão. Um elemento importante da pesquisa é organizar grupos de controle 
composto por estudantes que não obtiveram o ensinamento e treinamento sobre deliberação. Estes grupos estabelecerão o parâmetro para que possamos investigar se ensinar a deliberação produz um efeito positivo. Também haverá grupo de controle com e sem a presença de professor, a fim de medir o quanto os educadores contribuem ou se a aprendizagem por pares é mais produtiva. Todo o material será gravado e posteriormente transcrito para facilitar a análise dos momentos de deliberação. A análise dos dados se fará por meio dos métodos Deliberative Transformative Moments (DTM) (STEINER et al., 2004; STEINER, 2012) e Discourse Quality Index (DQI) (JARAMILLO, STEINER, 2014; STEINER et al., 2017), análises estatísticas e de conteúdo das discussões.

4) Ações para difusão e transferência do conhecimento: $O$ momento final da pesquisa é destinado às ações para difusão e transferência do conhecimento produzido pelo projeto. Um dos principais legados da pesquisa será um legacy website que conterá o passo-a-passo do experimento, bem como seus resultados. Iniciativas similares de módulos deliberativos implementados em escolas em outros países também foram concluídas com a criação desses repositórios, em que o material didático desenvolvido para as oficinas temáticas, textos sobre deliberação e outras informações são disponibilizados amplamente para o uso por possíveis multiplicadores do projeto.

O projeto se estrutura em duas fases, sendo a primeira delas dedicada à discussão e ensino dos princípios e estratégias para a deliberação em contextos de divisão de opiniões. Na segunda fase, os estudantes devem se engajar de forma prática em deliberação sobre temas sensíveis (violações de direitos, formas de violência, exploração, dominação, exclusão e temas políticos) em pequenos grupos e posteriormente em grupos mais amplos. Nessa fase, os estudantes podem exercitar a construção e apresentação de argumentos, habilidades necessárias para o exercício do papel de cidadãos.

\section{Conclusão}

Este artigo faz uma revisão de literatura sobre as experiências nacionais e internacionais de educação cívica, com foco nas iniciativas implementadas a partir do conceito de deliberação. Tal projeto tem o intuito de ensinar o que estamos chamando de capacidades deliberativas para estudantes do ensino público. 
Diferentemente de outras iniciativas nacionais e internacionais, tal programa não tem um foco conteudístico. O objetivo é capacitar alunos do período final do ciclo básico ao ensino médio com certas habilidades e atitudes que acreditamos serem fundamentais para o engajamento deliberativo: disposição para dialogar, deliberar e ouvir, tolerância e respeito com o ponto de vista do outro; capacidade para colocar-se no lugar do outro e atenção ao bem comum, entre outros. Especificamente, a partir de pesquisas prévias, o projeto busca criar consciência reflexiva sobre os comportamentos e atitudes que tornam a deliberação bem-sucedida ao explorar com os alunos o papel de justificações, histórias pessoais, sarcasmo, humor, silêncio e de líderes que dificultam ou facilitam o debate. Para tal, propomos um percurso metodológico que inclui a produção de materiais didáticos multimídia para as oficinas com os alunos, a proposição de atividades de simulação de comportamentos deliberativos e não deliberativos, o engajamento real dos alunos em práticas deliberativas sobre temas sensíveis, além da aplicação de questionários para dimensionar o impacto do programa educacional.

Acreditamos que nossa proposta se mostra inovadora não só por ser a primeira experiência brasileira de programa cívico baseado na noção de deliberação, mas, também, por propor uma abordagem diferenciada das iniciativas implementadas em outros países: não buscamos ensinar um conteúdo cívico específico, mas sim trilhar com os estudantes um percurso que seja capaz de construir capacidades para o diálogo, a reflexão e a resolução pacífica de conflitos. Nesse sentido, a proposta se constitui num projeto de intervenção social, mas uma intervenção que vem fundamentada por uma longa trajetória de pesquisas sobre comunicação política e deliberação em diversos espaços, incluindo os media tradicionais e os novos meios. Tal diálogo com a academia e a produção científica sobre o assunto nos fornece insumos para o planejamento do projeto, mas também se apresenta como um desafio.

Entendemos que esse processo de alargamento ou de ampliação da deliberação para a sociedade como um todo pode ser pensado em diversas frentes (BÄCHTIGER; WEGMANN, 2014; MANSBRIDGE et al., 2012; NIEMEYER, 2014). Aqui, estamos trilhando um caminho para pensar a ampliação da deliberação, essa forma exigente de comunicação, conforme definição de Habermas, a partir das escolas. $\mathrm{O}$ esforço para criar, de alguma forma, as condições para a construção de uma cultura deliberativa entre os jovens parece-nos muito promissor. Embora a busca pelo aperfeiçoamento da participação política e cidadã tenha gerado inúmeras experiências de deliberação em minipúblicos, parece-nos que o desafio aqui é de outra ordem: ao lidar com adolescentes no ambiente 
escolar. É, portanto, através da ampliação das fronteiras dos estudos sobre deliberação, com interfaces com a educação e outras áreas afins, que o projeto deverá continuar seu desenvolvimento.

\section{Referências}

ABRAMOVAY, M.; AVACINI, M.; OLIVEIRA, H. O bê-á-bá da intolerância e da discriminação. Brasília, DF: Unicef, 2002. Disponível em: <http://www.unicef.org/brazil/pt/Cap_02.pdf>. Acesso em: 20 outubro 2016

AVERY, P. G.; LEVY, S. A.; SIMMONS, A. M. M. Deliberating Controversial Public Issues as Part of Civic Education. The Social Studies, n. 104, p. 105-114, 2013.

BÄCHTIGER, A.; WEGMANN, A. Scaling up deliberation. In: ELSTUB, S.; MCLAVERTY, P. (Eds.). Deliberative democracy: Issues and cases. Edinburgh, UK: Edinburgh University Press, 2014. Pp. 118-135.

BORMANN, E. G. Symbolic convergence theory and communication in group decision making. In: Hirokawa, R.Y.; POOLE, M. S. (Org.) Communication and group decision-making. 2.ed. Beverly Hills, CA: Sage, 1996. Pp. 81-113.

COLEMAN, S.; MOSS, G. Under construction: The field of online deliberation research. Journal of Information Technology \& Politics, 9(1), 1-15, 2012.

DAYRELL, J; NOGUEIRA, M.A; VIEIRA, M.M.; RESENDE, J (Org.). Habitar escolas e suas margens. Portalegre, Portugal: Instituto Politécnico de Portalegre, 2012.

DENT, C. W.; GALAIF, J.; SUSSMAN, S.; STACY, A.; BURTUN, D.; FLAY, B. R. Demographic, psychosocial and behavioral differences in samples of actively and passively consented adolescents. Addictive Behaviors, v. 18, n. 1, p. 51-56, 1993.

DRYZEK, J. S. Foundations and Frontiers of Deliberative Governance. Oxford: Oxford University Press, 2010.

DRYZEK, J. S. Theory, Evidence, and the Tasks of Deliberation. In: ROSENBERG, S. (Ed.). Deliberation, participation and democracy: can the people govern? New York: Palgrave MacMillan, 2007. Pp. 237-250. 
DRYZEK, J. S; HENDRIKS, C. (2012). Fostering deliberation in the forum and beyond. In: FISCHER, F; GOTTWEIS, H. (eds.), The Argumentative Turn Revisited: Public Policy as Communicative Practice (Kindle location 564 of 8327). Duke University Press. Kindle Edition.

FELDMAN, L.; PASEK, J.; ROMER, D.; JAMIESON, K. Identifying Best Practices in Civic Education: Lessons from the Student Voices Program. American Journal of Education, v. 114, n. 1, p. 75-100, 2007.

FISHKIN, J. S. The voice of the people. New Haven, CT: Yale University Press, 1995.

GARCIA, L.; CAL, D.; MORAES, C (2017) Marcações de gênero no espaço escolar e a percepção das meninas. In: SANTOS, B.; FREITAS, L. (Orgs). Ser Menina no Brasil Contemporâneo: marcações de gênero em contexto de desigualdades. Curitiba: CRV, 2017, p. 81-100.

GASTIL, J.; DILLARD, J. P. The aims, methods, and effects of deliberative civic education through the National Issues Forums. Communication Education, v. 48, jul. 1999.

GERSHTENSON, Joseph; RAINEY JR, Glenn W.; RAINEY, Jane G. Creating better citizens? Effects of a model citizens' assembly on student political attitudes and behavior. Journal of Political Science Education, v. 6, n. 2, p. 95-116, 2010.

GIORDAN, M. The role of IRF exchanges in the discursive dynamics of email tutored interactions. International Journal of Educational Research, v. 39, p. 817-827, 2003.

HOLT, M.; KLEIBER, P.; SWENSON, J. Facilitating Group Learning on the Internet. New Directions for Adult and Continuing Education, n. 78, p. 43-51, 1998.

JARAMILLO, M. C.; STEINER, J. Deliberative transformative moments. A new concept as amendment to the DQI. Journal of Public Deliberation, v. 10, n. 2, 2014.

KIES, R. Promises and limits of web-deliberation. London, UK: Palgrave Macmillan, 2010.

KIES, R.; MANZ, P. (ed.). Is Europe listening to us? Success and failures of EU citizens consultations. Surrey, UK: Asgate, 2013.

MANSBRIDGE, J.; BOHMAN, J.; CHAMBERS, S.; CHRISTIANO, T.; FUNG, A.; PARKINSON, J.; WARREN, M. E. A systemic approach to deliberative democracy. In: PARKINSON, J; MANSBRIDGE, J. (Eds.). Deliberative systems. Cambridge, MA: Cambridge University Press, 2012. Pp. 1-26. 
NEBLO, M. A. Deliberative democracy between theory and practice. Cambridge, MA: Cambridge University Press, 2015.

NIEMEYER, S. Scaling up deliberation to mass publics: Harnessing mini-publics in a deliberative system. In K. Grönlund, A. Bächtinger \& M. Setälä (Eds.), Deliberative mini-publics: Involving citizens in the democratic process. Colchester, UK: ECPR Press, 2014. Pp. 177-202.

O'CONNELL, D. W.; MCKENZIE, R. H. Teaching the Art of Public Deliberation-National Issues Forums in the Classroom 1. PS: Political Science \& Politics, v. 28, n. 2, p. 230-232, 1995.

PARKINSON, J. Deliberating in the real world - Problems of legitimacy in deliberative democracy. Oxford: Oxford University Press, 2006.

PEREIRA, A. C. S.; DE ALBUQUERQUE WILLIAMS, L. C., DE BEM, F. P. Consentimento dos pais em pesquisas com escolares e a legislação brasileira. Interação em Psicologia, v. 16, n. 1, p. 51-61, 2012.

SAMUELSSON, M.; BOYUM, S. Education for deliberative democracy: Mapping the field. Utbildning \& Democrakti, v. 24, n. 1, p.75-94, 2015.

STASAVAGE, D. Polarization and publicity: Rethinking the benefits of deliberative democracy. Journal of Politics, v. 69, n. 1, p. 59-72, 2007.

STEINER, J., BÄCHTIGER, A., SPÖRNDLI, M., STEENBERGEN, M. R. Deliberative politics in action: analyzing parliamentary discourse. Cambridge: Cambridge University Press, 2004.

STEINER, J.; JARAMILLO, M. C.; MAIA, R. C. M.; MAMELI, S. Deliberation across deep divisions: Transformative moments. Cambridge: Cambridge University Press, 2017.

STEVENSON, H.; DRYZEK, J. S. Democratizing global climate governance. Cambridge, UK: Cambridge University Press, 2014.

STRANDBERG, K; GRÖNLUND, K. Online deliberation: Theory and practice in virtual mini-publics. In: GRÖNLUND, K; BÄCHTINGER, A; SETÄLÄ, M (eds.), Deliberative mini-publics: involving citizens in the democratic processes. Colchester, UK: ECPR Press, 2014, p. 93-113.

STROMER-GALLEY, J.; WICHOWSKI, A. Political discussion online. In: CONSALVO, M; ESS, C; BURNETT, R (Eds.), Blackwell handbook of internet studies. London, UK: Blackwell, 2011. Pp 168-187. 
TESTA, A. C.; \& COLEMAN, L. M. Accessing research participants in schools: a case study of a UK adolescent sexual health survey. Health education research, v. 21, n. 4, p. 518-526, 2006.

THOMPSON, D. F. Deliberative democratic theory and empirical political science. Annual Review of Political Science, n.11, p. 497-520, 2008.

THORNBERG, R. School democratic meetings: Pupil control discourse in disguise. Teaching and Teacher Education, n. 26, p. 924-932, 2010.

UNGER, J. B.; GALLAHER, P.; PALMER, P. H.; BAEZCONDE-GARBANATI, L.; TRINIDAD, D. R.; CEN, S.; JOHNSON, C. A. No news is bad news: Characteristics of adolescents who provide neither parental consent nor refusal for participation in school-based survey research. Evaluation Review, v. 28, n. 1, p. 52-63, 2004.

WARREN, M.E.; PEARSE, H. Designing deliberative democracy: The British Columbia Citizens'Assembly. Cambridge: Cambridge University Press, 2008. 